\title{
Ética, justicia e ideología en el desarrollo
}

\section{Carlos Zorro Sánchez}

\begin{abstract}
Resumen: Nos hemos acostumbrado a considerar como normales una serie de situaciones de injusticia extrema que son fuente de miseria y esterilización de las posibilidades humanas de vastos sectores de la población mundial. El presente artículo trata de mostrar que tales situaciones no resultan de la violación de principios éticos fundamentales por parte de algunos individuos u organizaciones aisladas, sino, justamente, de la aplicación de los criterios éticos que prevalecen hoy en la práctica económica y política. La vigencia de éstos se debe a que convienen a los intereses de los países y grupos económicos que dominan el escenario global, quienes los aprovechan de manera ideológica para mantener su poder, al margen del perjuicio que causan al desarrollo de las sociedades menos avanzadas económicamente. El texto concluye haciendo énfasis en la necesidad de replantear los criterios éticos que sirven para sustentar las decisiones económicas en el marco de la globalización actual.
\end{abstract}

Palabras clave: Ética, justicia, ideología, capitalismo, desarrollo

\section{Ethics, justice and ideology in the development}

\begin{abstract}
We have become accustomed to consider as normal a number of situations of injustice that are sources of extreme misery and sterilization of human possibilities of vast sectors of the global population. This article tries to show that such situations do not result from the violation of fundamental ethical principles by some individuals or organizations isolated, but because of the application of the ethical criteria that prevail in today's economic and political practice. They continue in force because it suits the interests of countries and economic groups that dominate the global stage, those who exploit them ideologically in order to maintain their power, regardless of the damage they cause to the development of economically less advanced societies. The text concludes by emphasizing the need to rethink the ethical criteria used to support business decisions in the context of globalization.

Key words: Ethics, justice, ideology, capitalism, development
\end{abstract}

Recibido: 25.06.2009

Aprobado: 15.07.2009

$* * *$

\section{La normalidad de las situaciones aberrantes}

Los informes del Banco Mundial, BM, el Programa de las Naciones Unidas para el Desarrollo, PNUD, la Organización de las Naciones Unidas

* Universidad de los Andes, Bogotá, Colombia. Email: czorro@uniandes.edu.co 
para la Agricultura y la Nutrición, FAO, el Programa Mundial de Alimentos, PMA, y la Organización Mundial de la Salud, OMOS, entre otros organismos internacionales, brindan un panorama aterrador de la situación del mundo hoy.

Aterrador, pese a que culturalmente nos ha sido impuesto un filtro que hace que las situaciones que se muestran, aberrantes desde cualquier punto de vista, pasen por ser completamente "normales” e inherentes a la naturaleza misma de las sociedades humanas. Aterrador, aunque los mismos organismos que informan acerca de esas situaciones tienden a matizarlas con un barniz de optimismo, que es por lo demás entendible y en ocasiones justificable, cuando desde una perspectiva histórica algunas las tendencias que han conducido a tales situaciones se han invertido y permiten augurar un mejor futuro. Es pertinente mirar algunos ejemplos entre tantos que infortunadamente abundan.

A juzgar por las reacciones de gran parte de la población mundial, incluidos la mayor parte de quienes manejan las riendas del poder económico y político, parece absolutamente normal que una de cada seis personas, más de mil millones de habitantes en el mundo, pasen hambre y otros tantos se encuentren desnutridos (Banco Mundial 2008) y que esa cifra se haya elevado en el último año, no sólo por efecto de la crisis económica global, sino del precio creciente de los alimentos en los mercados mundiales. Se estima que este incremento dejará a más de cien millones de personas adicionales en la pobreza absoluta. La mayor parte del aumento se registrará en el África subsahariana y en el Asia meridional, donde ya vive la mayor cantidad de personas en condiciones de pobreza extrema. (Naciones Unidas 2008b, p. 8, Organización de las Naciones Unidas para la Agricultura y la Alimentación, 2009) ${ }^{1}$.

No puede olvidarse que las recientes alzas se deben en gran medida a la reorientación del uso de cultivos antes destinados a la alimentación, o a su sustitución por otros aptos para la producción de biocombustibles (Organización de las Naciones Unidas para la Agricultura y la Alimentación, 2008: 84-93). Esta reorientación de una parte considerable de la actividad agrícola es el resultado de un conjunto de decisiones que han optado por sacrificar, al menos en el corto plazo, la satisfacción de las necesidades vitales mínimas de esos más de mil millones de habitantes, en beneficio de actividades económicamente más rentables y ciertamente relevantes, aunque discutibles en términos de la prioridad que se les ha otorgado.

\footnotetext{
${ }^{1}$ Estas cifras coinciden con las de la Organización de las Naciones Unidas para la Agricultura y la Administración, FAO, el Programa Mundial de Alimentos, PMA y el Fondo Internacional de Desarrollo Agrícola, FIDA. Cabe advertir por lo demás que este artículo no entrará en el amplio debate en curso con relación al concepto de pobreza y que cuando haga referencia a este fenómeno, adoptará las definiciones de los organismos o autores que cite. Un buen estado del arte sobre este debate puede encontrarse en Shaffer (2008).
} 
Si la persistencia del hambre extrema a los niveles señalados es percibida por la mayor parte de la población como un fenómeno que resulta normal a fuerza de oírlo repetir, no es sorprendente que se escuche con absoluta indiferencia que, de acuerdo con el Banco Mundial (2009), en 2005 el ingreso percibido por otros mil cuatrocientos millones de personas, menos de dos dólares/día (US\$2,00), les impedía tener acceso a varios de los servicios que en el mundo contemporáneo resultan indispensables para mantener condiciones de vida mínimamente aceptables. Este número de personas probablemente no ha disminuido, ya que su tendencia decreciente era muy débil y probablemente ha sido contrarrestada por la reciente crisis. De paso obsérvese que estos mil cuatrocientos millones de personas tienden a coincidir con los mil millones de habitantes que, según el mismo Banco, aunque no padecen hambre física, se encuentran desnutridos.

Por lo demás, tampoco resulta particularmente interesante para la mayoría de la gente, que en 2008, según el mismo Banco Mundial (2009), siguiera habiendo 190.000 niños menores de cinco años que morían semanalmente a causa de enfermedades prevenibles; 10.000 mujeres que fallecían cada semana por complicaciones del embarazo, fácilmente tratables; casi dos millones de personas que morían de tuberculosis y alrededor de un millón de paludismo, enfermedades éstas que han tendido a resurgir como consecuencia de las condiciones sanitarias de los países más pobres ${ }^{2}$. Más aún, talvez apenas genere un gesto de desaprobación el hecho de que -todavía siguiendo al Banco Mundial (2009 b)-, entre 2009 y 2015, podrían morir entre 200.000 y 400.000 niños pequeños más por año en todo el mundo como resultado de la crisis. Si no se toman medidas de inmediato, para 2015 esto podría sumar un total de entre 1,4 y 2,8 millones más de muertes de niños pequeños.

Lo anterior por una parte ha llevado al presidente del Banco Mundial, Robert B. Zoellick a afirmar que: "La crisis económica mundial amenaza con convertirse en una crisis humanitaria en muchos países en desarrollo a menos que puedan tomar medidas enfocadas en hacia la protección de la gente vulnerable de sus comunidades”3, pero, por otra parte, provoca en la inmensa mayoría de quienes tienen acceso a sus palabras un gesto que denota a la vez conformidad e impotencia.

No es necesario abundar en otros ejemplos que, como ya se anotó, podrían multiplicarse y que generan un profundo cuestionamiento ético en la medida en que a veces son desencadenados y en la mayoría de las veces tolerados por quienes tendrían la responsabilidad y en ocasiones la posibilidad de remediarlos: violación de los derechos más elementales como el

\footnotetext{
${ }^{2}$ Recuérdese que alrededor de la mitad del mundo en desarrollo carece de acceso a instalaciones básicas de saneamiento.

${ }^{3}$ Hay que reconocer la insistencia de estos llamados del actual Director del Banco, registrados, entre otros lugares, en la página web http://www.bancomundial.org/temas/ preciosalimentos/archivo.htm
} 
que le permitiría a cualquier persona determinar libremente el lugar de su residencia, carencia de oportunidades educativas para sectores todavía muy grandes de la población mundial, guerras y conflictos violentos internos e internacionales, muchas veces dirigidos a preservar o conquistar nuevos privilegios para quienes ya disponen de ellos.

Sin embargo, si se observa la otra cara de la moneda, tampoco parece sorprender ni generar ningún tipo de reacción entre la mayor parte de la población y, menos aún, entre la mayoría de sus líderes, que la situación esbozada coincida con la existencia de una gran riqueza material, concentrada en un número relativamente pequeño de países y controlada por una ínfima proporción de personas. Esta riqueza, por lo demás, es tan grande que según los análisis realizados previamente a la adopción de los Objetivos del Milenio a los que se hará referencia en breve, bastarían alrededor de cinco años de aplicación sistemática de los recursos mundiales para erradicar la miseria extrema que sumerge a cerca de la quinta parte de la humanidad. Pero el hecho de que no sea la falta de recursos materiales la que impide superar las carencias enunciadas y que éstas hayan tendido a perpetuarse y aún a crecer en medio de un mar de abundancia, sólo genera reacciones de insatisfacción y protesta en pequeños grupos de "intelectuales” o "activistas”, cuyas voces difícilmente son tomadas en serio.

En efecto, para la mayor parte de los que tendrían las herramientas necesarias para convertir esas denuncias en detonantes capaces de cambiar el estado de cosas imperante, el hecho de que haya quienes se atreven a cuestionarlo y a veces a confrontarlo es apenas índice de su "ignorancia de las leyes científicas que guían los comportamientos humanos y los procesos que de ellos se derivan”, de su “envidia”, su "populismo” u otras expresiones tendientes a estigmatizar los planteamientos incómodos. Más aún, quienes los proponen son con frecuencia víctimas del rechazo y aún, en ocasiones, de la abierta persecución de quienes detentan el poder político y económico.

Si bien durante la mayor parte del siglo XX este tipo de reacciones pudo sustentarse en la defensa de las libertades humanas que el capitalismo percibía amenazadas por el sistema comunista, particularmente bajo la forma adoptada por la Unión Soviética, la estrepitosa caída de éste y la refrescante ola de libertad que propagó por el mundo parecería haber creado condiciones para hacer frente, desde la óptica de una sociedad no amenazada, a la realidad de miseria e iniquidad predominantes en el mundo. Pero no todas las expectativas suscitadas por este acontecimiento, entre ellas esa búsqueda por un nuevo orden global más equitativo, se materializaron. Tal como lo señala Short (2009: 8,9): “El fin de la guerra fría generó esperanzas de una reducción en el gasto de defensa y de una era de cooperación internacional. Pero en la práctica, los 1990 fueron desordenados y sangrientos": guerras internas e internacionales, crisis humanitarias como la de Somalia en 1992, genocidios en los Balcanes y en Ruanda; conflictos internos depredadores en Asia, África y Latinoamérica que siguen proyectándose cuando está para iniciarse el tercer lustro del siglo XXI, sin 
contar con los problemas de pobreza y miseria ya mencionados que persisten en medio de una indiferencia generalizada y de un bloqueo más o menos solapado de muchos de los grupos más poderosos a los esfuerzos bien intencionados de personas y organismos empeñados en cambiar la situación descrita pero cuya eficacia dista mucho de ser la esperada.

Frente a estos esfuerzos cabe reconocer que especialmente en las tres últimas décadas, el crítico deterioro de las condiciones en varias regiones del mundo -que por lo demás pone en riesgo la seguridad de las sociedades privilegiadas tal como lo evidenció el atentado contra las Torres Gemelas en septiembre de 2001-, ha logrado que algunas voces contestatarias vuelvan a ser oídas y amplificadas en los pronunciamientos de un número creciente de organismos adscritos a las Naciones Unidas, algunos de los cuales, como el Banco Mundial, han dado un giro sustancial a su discurso. A ellos se han venido sumando poco a poco diversas organizaciones no gubernamentales, varias de alcance global. No obstante, es claro que los llamados cada vez más fuertes de estos organismos durante no menos de treinta años no han producido cambios contundentes en las condiciones descritas $^{4}$, ni en las políticas para afrontarlas. Y es igualmente preocupante que esto ocurre sin que la mayor parte de los gobernantes y líderes de los países afectados por esta situación hayan reaccionado de manera enérgica y organizada.

El preocupante balance de esfuerzos y logros en el camino hacia los llamados “Objetivos del Milenio”, que constituyen sin lugar a dudas la propuesta más sólida dirigida a paliar el estado de cosas arriba esbozado y cuyo texto fue suscrito por la mayor parte de los gobernantes de los países económicamente más desarrollados, brinda un claro índice de la apatía que ha suscitado este llamado entre quienes se han comprometido a convertirlo en realidad. En palabras del Banco Mundial: "Según las tendencias actuales, es improbable que se pueda alcanzar la mayoría de los ODM sobre desarrollo humano a nivel mundial”. (2009 b: 4)

De acuerdo con el Informe del Grupo de Tareas sobre el logro de los objetivos de desarrollo del Milenio de 2008, (Naciones Unidas, 2008, c: 9), "existe un amplio desfase en el cumplimiento de los compromisos dirigidos a alcanzar la meta contenida en los objetivos de desarrollo del Milenio... Los esfuerzos para incrementar la asistencia oficial para el desarrollo han sufrido un revés. En 2007, los únicos países que habían alcanzado o superado la meta de las Naciones Unidas de dedicar a esta asistencia un $0,7 \%$ de su ingreso nacional bruto eran Dinamarca, Luxemburgo, Noruega, los Países Bajos y Suecia. El esfuerzo medio realizado por los 22 países miembros del Comité de Asistencia para el Desarrollo de la Organización de Cooperación y Desarrollo Económicos (OCDE) fue tan sólo del

\footnotetext{
${ }^{4}$ Salvo en un grupo minoritario de países, principalmente China cuyo peculiar sistema social y económico ha dado lugar a procesos de desarrollo sui generis que impiden incluirla dentro de la lógica que prevalece actualmente.
} 
0,45\% del ingreso nacional bruto, pero, ponderado por el tamaño de sus economías, el flujo total neto de las ayudas de los miembros del Comité representaba únicamente un $0,28 \%$ de su renta nacional combinada.”

Más aún, el mismo informe destaca que si bien el flujo de ayuda aumentó constantemente a partir de 1997, hasta alcanzar su punto máximo de 107.000 millones de dólares de los EE.UU. en 2005, gracias al excepcional alivio de la deuda que tuvo lugar ese año, desde entonces, la asistencia neta oficial para el desarrollo a precios constantes descendió un 4,7\% en 2006 y otro 8,4\% en 2007 (Ibidem).

Por otra parte, ha sido muy lento el progreso hacia la configuración de un sistema comercial y financiero "abierto, basado en normas, previsible y no discriminatorio", que brinde "acceso libre de aranceles y cupos a las exportaciones de los países menos adelantados”. Señala el mismo informe de las Naciones Unidas que uno de los objetivos de la Ronda de Doha de negociaciones comerciales iniciadas en 2001 era abordar las necesidades de los países en desarrollo de acuerdo con un "Programa para el Desarrollo” y que siete años más tarde, ha sido imposible concluir una ronda de desarrollo en el ámbito del comercio (Ibidem: 11). Tampoco ha sido posible introducir ningún cambio relevante en la anarquía que caracteriza los flujos transnacionales de capitales y que ha afectado gravemente los procesos de desarrollo de varios países. Esto, sin embargo, no es de extrañar si se tiene en cuenta que el ámbito de los intercambios comerciales y financieros internacionales aloja gran parte de los mayores intereses de las grandes corporaciones económicas y de los estados económicamente más poderosos.

Desde otra perspectiva, es claro que la enorme desigualdad en la distribución del ingreso mundial, que explica en gran parte las carencias anotadas en los apartes anteriores, sigue creciendo mientras discuten sobre ella diversos académicos, algunos líderes “radicales” y organismos internacionales, sin que sus reflexiones, protestas o propuestas hayan conducido a acciones efectivas dirigidas a modificarla. Señala el Informe sobre el Desarrollo Mundial 2005, que “el ingreso total de los 500 individuos más ricos del mundo es superior al ingreso de los 416 millones más pobres. Más allá de estos extremos, los 2.500 millones de personas que viven con menos de dos dólares al día -y que representan el 40\% de la población mundial- obtienen sólo el 5\% del ingreso mundial. El 10\% más rico, casi todos ellos habitantes de los países de ingresos altos, consigue el 54\%" (PNUD, 2005: 4). Y prosigue el PNUD señalando, como corolario de la extrema desigualdad mundial, el que incluso cambios modestos en la distribución desde arriba hacia abajo podrían tener un efecto notable sobre la pobreza: conforme a los datos disponibles se calcula que el monto necesario para llevar a mil millones de personas a superar el umbral de pobreza extrema de un dólar al día es de US\$300.000 millones, cifra que representa el 1,6\% del ingreso del 10\% más rico de la población mundial (Ibidem: 5).

Naturalmente, este monto describe una transferencia estática mientras que la reducción sostenible de la pobreza requiere un proceso dinámi- 
co que involucre el esfuerzo de los países y personas de menores ingresos; no obstante, el tomarlo como referencia es útil para concluir que si no se han logrado los cambios necesarios no es debido a falta de recursos ni a la "sobrepoblación” y, si esto fuere así, resulta ineludible preguntarse acerca de las razones por las cuales ni siquiera se ha planteado la posibilidad de examinar vías similares a la que con ánimo meramente ilustrativo señala el PNUD, obviamente adecuadas para hacer sostenibles sus efectos, con miras a cambiar al menos algunas de las situaciones más aberrantes ya descritas.

Si un individuo deja morir un ser humano herido en un accidente de tránsito, es castigado por la ley y censurado por la sociedad. Resulta por ello desconcertante que representantes de grupos económicos que podrían contribuir a frenar la muerte de millones de individuos y no lo hacen ni tienen la menor intención de hacerlo, lejos de ser censurados sean puestos como ejemplo para la sociedad, sean invitados, adulados y condecorados por los gobiernos y admirados por gran parte de la población. Más aún, con frecuencia los mismos organismos que cuestionan los resultados de la acción de tales grupos, cuando buscan salidas a los impasses generados acaban recomendando que se respalden su actividad y sus inversiones, sin plantear restricciones de fondo para evitar que se reproduzcan los efectos negativos que pretenden combatir.

Aunque la lógica del razonamiento anterior podría cuestionarse por el hecho de que los procesos sociales no son asimilables a los comportamientos individuales, no por ello deja de tener validez la pregunta acerca del por qué de esa real o aparente inconsistencia en la aplicación de los principios éticos de la que, por lo demás participa, así sea de manera inconsciente la mayoría de las personas. Si el ejercicio de la actividad económica conduce a situaciones intolerables desde el punto de vista humano, como las que se han mencionado anteriormente ¿Cómo puede valorarse ese ejercicio desde el punto de vista ético? ¿Cabe sustentar la persistencia de su aplicación desde una perspectiva ética? En este caso ¿Qué validez tiene esa o esas sustentaciones? ¿O los referidos problemas son simplemente atribuibles a un ejercicio corrupto de la actividad económica? ¿ $\mathrm{O}$ a un comportamiento completamente al margen de la ética? artículo.

A estos interrogantes se referirán los apartes posteriores de este

\section{Los fundamentos de la ética dominante en el mundo occidental contemporáneo}

Es frecuente escuchar en ciertos medios que gran parte de los comportamientos que afectan negativamente los procesos sociales contemporáneos se deben a la "falta de ética". Se sostiene en este artículo que el problema no es que no exista una ética sino que la corriente ética que domi- 
na conduce a decisiones cuyas consecuencias son, entre otras, las que se enunciaron brevemente en el numeral anterior.

Si se parte de la aceptación de que cada ser humano tiene un cierto grado de libertad, así sea mínimo, que sus acciones en la mayoría de los casos no están determinadas de manera absoluta por fuerzas externas ${ }^{5}$, hay que admitir que las decisiones que toma obedecen a determinados criterios, implícitos o explícitos, cualesquiera que sean. Esos criterios son de naturaleza ética y se desprenden bien sea de la valoración que se le otorgue al acto que va a realizarse (frente al concepto de lo bueno y a los principios que de él se desprenden -deontología-) o de la valoración que se dé a las consecuencias de éste bien sea a largo plazo (teleología) o a corto plazo (utilidad). Naturalmente, es posible romper las orientaciones del marco ético adoptado y en este caso se habla de corrupción o falta de ética pero siempre con referencia a esas guías de conducta.

Con base en lo anterior resulta necesario examinar primero cuál es la naturaleza de la ética que prevalece en la práctica económica contemporánea, y cuáles los resultados que se desprenden de la aplicación de sus orientaciones y si ellos no correspondiesen a la realidad observada anteriormente, tratar de detectar cuáles son los vicios que han llevado a la práctica económica a generar tales resultados.

\section{Entre la ética calvinista y la ética de la economía como "ciencia”}

Ya en la primera década del siglo XX, Max Weber (c2001) subrayaba cómo la idea calvinista de la predestinación había impregnado el pensamiento y la práctica del capitalismo, fortaleciendo sus raíces individualistas y los criterios utilitaristas que guían las decisiones de los agentes económi$\cos ^{6}$. Si estar entre los "elegidos" por Dios se manifestaba en el éxito en la vida terrenal, lo importante era lograr resultados inmediatos capaces de mostrar esa "predestinación”; de esa manera el criterio de la inmediatez en los logros derivados de las acciones entró a prevalecer en el momento de valorarlas desde el punto de vista ético; con ello también se destacó el

\footnotetext{
5 "Las llamadas ciencias sociales, incluyendo la economía, no son deterministas; simplemente proponen una tendencia que no anula la libertad y la responsabilidad del agente”. En palabras de Aranguren (19 p.24) aunque es cierto que de alguna manera hay “... un condicionamiento económico de la moral... la Economía no debe olvidar, como con frecuencia lo parece, que los actos económicos son siempre actos humanos y, por tanto, en un sentido primario de la expresión, morales; es decir, libres, elegidos y de los que se es responsable.” Y parafraseando al mismo autor cabe señalar que los actos económicos no por serlo dejan de ser humanos.

${ }^{6}$ Esta tesis, ampliamente aceptada aunque controvertida por algunos, ha dado lugar a distintas publicaciones, entre las cuales cabe mencionar uno de los libros escritos por el ex presidente colombiano Alfonso López Michelsen (1966).
} 
carácter individual de los logros: cada quien debe demostrar, independientemente de los demás, su predestinación.

La progresiva asimilación del éxito con lo material sirvió de base a la ética del capitalismo: es bueno lo que se acerque a maximizar los rendimientos de la inversión; el utilitarismo pasa en consecuencia a ser el fundamento ético de las acciones individuales. Sin embargo, los padres de la llamada “ciencia económica” no desechaban su preocupación por los efectos de los procesos económicos sobre el conjunto de la sociedad a largo plazo. No es extraño por lo tanto que Adam Smith haya dedicado una parte considerable de su obra a tratar de demostrar como la "mano invisible del mercado” llevaba a una situación óptima desde el punto de vista social, a partir de las acciones racionales de los agentes individuales. Tampoco John Stuart Mill, que además de economista fue filósofo y uno de los padres de la visión contemporánea del utilitarismo, junto con Bentham, dejó de preocuparse por el sentido ético de las actividades económicas. Aunque consecuente con su posición reconoce en la maximización del beneficio individual el móvil principal de las acciones humanas, no sólo subraya que aquel no necesariamente se "mide" en términos de bienes materiales pues a él confluyen "valoraciones” de orden psíquico, estético, intelectual y aún espiritual, sino que muestra que desde esta perspectiva es posible conciliar egoísmo y altruismo. Este tipo de reflexiones ocupa a varios autores desde la perspectiva liberal a propósito del tema de la justicia sobre el que se volverá en breve.

Pero fue precisamente la pretensión de hacer de la economía una “ciencia” lo que relegó las preocupaciones éticas a un plano secundario. En efecto, si la economía es ciencia, como lo afirma el discurso dominante hoy en la teoría y la práctica política, su lógica está en el mundo del “ser” y no en el del “deber ser”; en otros términos sus procesos están sujetos a relaciones de causalidad según las cuales “si es A es B”. Según este planteamiento, el ser humano es un "homo economicus" sujeto a las leyes del mercado, de las cuales no puede escapar sin que su comportamiento se convierta en algo irracional, y si precisamente es el respeto a esas leyes lo que le permite maximizar los rendimientos de sus acciones conforme a los planteamientos de la ética utilitarista, su acción debe ser guiada por las orientaciones del mercado y su compromiso ético es simplemente ajustarse a éstas. (Arnsperger, Van Parijs, 2002: 12 y 13, entre otros).

Si la economía es una ciencia, el agente económico no tiene dilemas éticos. Debe limitarse a reaccionar como libremente considere que debe hacerlo ante las indicaciones del mercado, que en términos éticos no son “principios” sino “leyes”, a imagen y semejanza de las leyes de la naturaleza, y no preocuparse por las consecuencias de sus actividad económica ya que son ineludibles como resultado de tales "leyes", ni por la bondad de cada uno de los actos que realiza ajustándose a éstas: es bueno lo que indica el mercado y el seguir sus pautas conducirá no sólo a su éxito individual sino al beneficio de toda la sociedad. En otros términos, no hay acciones justas o injustas en materia económica cuando quienes las realizan respetan 
las indicaciones del mercado, por cuanto ni los resultados que eventualmente puedan apreciarse como negativos de tales acciones son buscados por esas personas, ni ellas tienen control sobre los procesos que conducen a tales resultados. En palabras de Ovejero (1994:54), para quienes participan de esta forma de pensar, “...la justicia radica en respetar los procedimientos... no en evaluar los estados finales a los cuales conduce su aplicación”. Pero aún si se aceptara una evaluación de tipo teleológico, no podría hablarse de injusticia en los comportamientos de quienes se ajustan a las orientaciones del mercado, cuando las leyes que lo rigen indican que, precisamente, es el acatamiento de éstas lo único que garantiza en el mediano y el largo plazo un mejoramiento en la calidad de vida del conjunto de los miembros de una sociedad dada.

Esta idea subyace bajo las expresiones de los principales autores que defienden el paradigma del mercado como referente fundamental de las decisiones humanas. Naturalmente cada uno de ellos presenta sus ideas de manera diferente y no se pretende aquí dar una idea de la riqueza y complejidad de sus planteamientos. Simplemente, se enunciarán algunos rasgos claves de éstos con miras a sustentar la tesis central de este artículo.

\section{Utilitarismo y liberalismo}

Para el utilitarismo clásico, consecuente con su planteamiento básico y desde la perspectiva de la práctica política, el Estado debe facilitar el camino para que el mayor número de personas alcance la máxima felicidad posible, ya que la máxima felicidad del conjunto se logra maximizando la felicidad de cada individuo. La maximización del todo -felicidad del conjunto social- exige maximizar la de cada una de sus partes, o sea los, individuos que lo integran

Esta visión fue desde un principio objeto de múltiples cuestionamientos debido a que no es difícil demostrar que la maximización del bienestar de cada uno de los individuos que hacen parte de una colectividad no necesariamente conduce a la maximización del bienestar de ésta y que, de hecho, la maximización sin restricciones puede llevar a situaciones claramente indeseables. Con el fin de resolver los problemas puestos en evidencia, diversos autores, en su mayor parte vinculados a la corriente de la "economía del bienestar”, han intentado dar respuestas al tema de la agregación de preferencias individuales -no necesariamente referidas a bienes materiales- como forma de llegar a una situación óptima en términos de bienestar colectivo. Desde Pareto hasta Rawls y Sen, pasando por Arrow, entre otros, se han propuesto soluciones que en una u otra forma exigen restricciones a la expresión de las preferencias individuales y que incorporan elementos éticos no directamente desprendidos de las orientaciones del mercado. ${ }^{7}$

${ }^{7}$ Sen (1989: 48-74) analiza aspectos teóricos y prácticos del utilitarismo. Una breve y bien
lograda síntesis de algunos de los planteamientos más importantes del debate se encuentra 
Desde una perspectiva diferente, Nozick (c1988), adopta como supuesto de partida que la libertad constituye el valor supremo del ser humano, en el que radica la esencia de su dignidad, que no puede ser burlada en nombre de ningún imperativo colectivo. Esta dignidad reside en ejercicio soberano de libertad de elección en el marco de un sistema coherente de derechos. El punto de partida del ejercicio de esa libertad es el ser un individuo; el único límite es la libertad del otro, de aquel con quien está llamado a convivir.

Ahora bien, siendo el mercado la institución que ha demostrado ser la mejor para garantizar la supervivencia y el desarrollo de la sociedad, ha llegado a convertirse en el ámbito privilegiado de expresión de los comportamientos humanos y, por ende, es en él donde ha de expresarse más a plenitud esa libertad. No es pues extraño que el principio fundamental del mercado ideal, el de competencia perfecta, sea el de la libertad de los agentes económicos, oferentes y demandantes, para intervenir en él sin presiones de ninguna índole. Por esta razón es la protección de este valor superior lo que ante todo debe guiar la acción de quienes tienen la responsabilidad de garantizar la convivencia social.

Pero el agente económico actúa en el mercado mediante objetos externos; de ahí se desprende la necesidad de que la organización política, en este caso el Estado, producto y garante del pacto social, le reconozca el derecho a adquirir esos objetos, bienes y servicios mediante instrumentos compatibles con el funcionamiento del mercado, $\mathrm{y}$ a utilizarlos como a bien tenga, sin restricciones de ninguna índole, siempre que en el proceso respectivo no viole la libertad de los otros, entendida ésta como ausencia de coerción física. Expresado en otra forma, todos los seres humanos tienen derecho a no ser interferidos por nadie en sus decisiones sobre uso y disposición de la propiedad adquirida según la ley. Nadie puede ser privado, sin su consentimiento, de ningún fruto de su trabajo personal. Hacerlo sería hurto, inclusive si quien pretende afectar la propiedad es el mismo Estado, independientemente de las razones que aduzca para hacerlo.

Friedrich Hayek ha sido uno de los autores que más se ha ocupado del tema económico desde una perspectiva filosófica. En su análisis subraya que sólo hay responsabilidad cuando las consecuencias de una acción individual son previsibles y manejables por quien la realiza. Ahora bien, como los efectos resultantes de las intervenciones de los agentes en el mercado no son buscados por ellos sino que son el resultado de procesos regidos a su vez por leyes que escapan a su control de tales agentes, no les son imputables a éstos los resultados que toman en función de las orientaciones del mercado, (Hayek, c1996) así como nadie puede responder por el hecho de que un cuerpo caiga por efecto de la ley de la gravedad. Pero su análisis va más allá y mediante una aproximación histórica concluye que a lo largo

en Zañartu (1994). También están los elementos de esta discusión en Arsnperger y Van Parijs (2002 pp. 29-42), entre otros 
de los siglos la humanidad fue construyendo un orden alrededor del mercado, orden que obedece a reglas específicas pero que es superior a cualquier orden concebido por la mente porque es resultado de la evolución misma de la humanidad. A medida que ese orden, producto del encuentro "entre el instinto y la razón”, surgido a la manera de Smith de la acción de una especie de mano invisible, se ha venido consolidando, el ser humano ha ido encontrando las reglas de la libertad, cuya forma concreta es la justicia, pero no la justicia que resulta de la norma escrita, sino la que surge del aprendizaje de las interacciones humanas en el curso de la historia y del uso de esos aprendizajes hasta convertirlos en reglas morales. Es entonces el orden surgido en torno al mercado el que ha venido, a lo largo de los siglos a definir las reglas morales y no tiene sentido cambiarlas en función de planteamientos puramente racionales o aún instintivos como lo sería la idea de "solidaridad". (Tomado de Angulo 1994: 82)

Sintetizando y simplificando, el nexo entre la economía y la ética, llevado al extremo quedaría circunscrito a dos aspectos: el ejercicio por parte del agente económico, de su libertad absoluta para actuar con miras a maximizar su propio beneficio sin quebrantar las orientaciones tanto fundamentales como coyunturales impartidas por el mercado ${ }^{8}$ y la vigilancia que cada individuo está llamado a ejercer para que los demás se ajusten estrictamente a tales normas. Las consecuencias de los actos no importan siempre que estos se hagan en ejercicio de la libertad.

Es preciso sin embargo reconocer que no todos los principales economistas teóricos del capitalismo participaron de esta visión restringida de la relación entre economía y ética. Es así como en 1890 Alfred Marshall en sus "Principios de Economía” afirma:

Las fuerzas éticas están entre aquellas que el economista tiene que tomar en cuenta. Se han hecho intentos de construir una ciencia abstracta que trate de las acciones de un "hombre económico" que no esté bajo influencias éticas y que persigue astuta y enérgicamente pero también mecánica y egoístamente, la ganancia pecuniaria. Pero no han tenido éxito ni lo han llevado completamente a cabo ${ }^{9}$

Más aún, la pretensión de hacer del mercado el referente único de los comportamientos económicos queda desprovista de fundamento si se tiene en cuenta, entre otras consideraciones, que no todas las preferencias se manifiestan en él ya que, por una parte, existen bienes y servicios que no se transan en éste (González, 2006:108), y por otra, en palabras de Ovejero

\footnotetext{
${ }^{8}$ Entre las primeras se encuentran algunas normas de conducta frente a los competidores y a los clientes: no a la competencia desleal, no al engaño bajo ninguna de sus formas, por ejemplo, que constituyen la expresión deontológica de la economía de mercado. De todas maneras esto implica como señala González (2006, p. 106) que, por ejemplo, el utilitarismo de Bentham no cabe en el espacio de los egoístas puros.

${ }^{9}$ Citado por Zañartu (1994 b): 104.
} 
(1994), en él sólo se expresan las preferencias de quienes tienen dinero para manifestarlas, lo que por definición excluye a parte considerable de la humanidad ${ }^{10}$.

\section{La justicia}

Tanto al comentar anteriormente los planteamientos de Hayek como en la referencia de Ovejero (1994:54), se ha introducido un nuevo elemento en el análisis de la relación entre ética y economía: el concepto de justicia.

Desde la perspectiva occidental cabe remontarse hasta la época del Código de Hammurabi para encontrar los orígenes de las ideas de justicia que se disputan el predominio en el mundo contemporáneo y ubicarse luego en Aristóteles para acercarse a formulaciones relativamente cercanas de esas ideas, directamente relacionadas con la ética al ser la justicia un valor ético fundamental. De este filósofo se generalizó en Occidente la distinción entre la justicia conmutativa y la justicia distributiva. La primera consiste en asegurar que en una determinada transacción de carácter civil o comercial, cada una de las partes reciba un valor equivalente al que le entregó a la otra; este valor habitualmente coincide con el que las partes consignen en documentos suscritos libremente o en acuerdos verbales. La justicia distributiva, por su parte, implica dar a cada quien lo que le corresponde, en función de valores sociales que atribuyen una determinada ponderación a elementos tales como los méritos o necesidades de la persona.

La justicia conmutativa, de carácter esencialmente privado y regulada hoy por el derecho civil, exige el cumplimiento de arreglos pactados institucionalmente entre dos partes interesadas que actúan libremente por cuanto no son objeto de coacción física, en tanto que la justicia distributiva exige un referente social. La primera tiene en consecuencia su origen en transacciones individuales mientras que la segunda sólo puede entenderse en un determinado contexto social.

Ahora bien, así como existe un cierto consenso en torno a la noción de justicia conmutativa, hay muchas y muy diversas aproximaciones, en

\footnotetext{
${ }^{10}$ Aún si se aceptase al mercado como guía fundamental de las decisiones económicas, la existencia de bienes muy útiles, como el aire para citar sólo uno, que están por fuera del mercado, implica que éste no puede pretender ser la orientación única de los comportamientos económicos y que en casos como éstos “...el análisis económico ya no puede ocultar la relevancia de lo ético.” (González, 2006: 108). Esta consideración se refuerza cuando se pasa de la elección individual a la elección social que implica, por ejemplo, la decisión con respecto al tipo de sociedad que se quiere, cuestión ésta que da comienzo a la reflexión de Arrow sobre la elección colectiva y que genera de entrada opciones valorativas por fuera del mercado. (Ibidem: 105-111).
} 
ocasiones muy diferentes entre sí, al concepto de justicia distributiva, una de cuyas expresiones es la llamada “justicia social”.

Indudablemente ha sido John Rawls el autor cuyas tesis han marcado de manera más profunda la discusión contemporánea sobre la justicia dentro de la lógica de la democracia liberal.

Desde su punto de vista, los ideales de libertad e igualdad pueden lograrse simultáneamente mediante de la justicia. Una sociedad justa es aquella que asegura a cada quien las condiciones de una vida buena: bienes primarios naturales (salud, talentos) y sociales (libertades, oportunidades de acceso a posiciones sociales y ventajas socioeconómicas). Cabría afirmar así que la justicia es una cualidad que permite a todos los integrantes de una sociedad disponer de los medios que les permiten realizarse como seres humanos.

Según Rawls (1995 ), hay justicia en la medida en que se cumplan dos principios que pueden ser enunciados en la siguiente forma: a. Toda persona tiene un derecho igual al conjunto más extenso de libertades fundamentales que sea compatible con un conjunto igual de libertades para todos; b. Las eventuales desigualdades deben satisfacer dos condiciones: la de la diferencia, conforme a la cual las desigualdades deben maximizar el beneficio de los menos aventajados y la de la igualdad equitativa en virtud de la cual las desigualdades -que son perfectamente válidas porque los seres humanos si bien iguales en su naturaleza difieren en sus cualidades específicas- deben ligarse a posiciones y funciones a las que todos tienen igual acceso.

Como puede apreciarse, el planteamiento de Rawls también se aleja de la idea de que la economía es simplemente un compendio de leyes inmutables vinculadas a las indicaciones del mercado, por fuera de las cuales el comportamiento humano es irracional. En efecto, la aplicación de los principios de la justicia no conduce a una respuesta única; el ser humano tiene un margen más o menos amplio de discrecionalidad en su aplicación y, por ese mismo hecho, se ve sometido a tomar decisiones que necesariamente tienen un carácter ético en cuanto no están rígidamente predeterminadas.

Ahora bien, desde la perspectiva de la organización social la pregunta que surge es si el contrato entre particulares, basado en los principios de la justicia conmutativa (contrato civil) es suficiente para asegurar a todos el ejercicio de sus derechos como parte de una organización social como el Estado. La respuesta es negativa ya que el contrato civil “....aporta los fundamentos igualitarios sustentando la estructura de desigualdad social. Aunque haya igualdad en la capacidad jurídica sigue siendo necesario actuar sobre la estructura social para garantizar eficazmente la autonomía individual frente a los límites que impone el entorno social.” (Procacci, 1999: 21). Es pertinente señalar como uno de los padres de la economía marginalista, León Walras, considera que la propiedad estatal de la tierra es condición necesaria para el funcionamiento del mercado. "En este sentido 
la justicia distributiva es una precondición para que el mercado sea compatible con la justicia conmutativa. Del mercado no se deriva la justicia distributiva, sino que ésta es una precondición del mercado...” (González, 2006: 121).

\section{El paradigma del desarrollo}

La evolución de las sociedades humanas ha sido objeto de reflexión a todo lo largo de la historia y es el paradigma del "desarrollo" el que ha venido imponiéndose en la reflexión académica y en la práctica política de los países occidentales desde mediados del siglo XX. Por razones que no es del caso entrar a examinar aquí, este paradigma ha venido impregnando el pensamiento global, inclusive en sociedades cuyas culturas estuvieron por mucho tiempo alejadas del tipo de visión predominantemente materialista, individualista y liberal que ha caracterizado el pensamiento, aunque muchas veces no la política de los mencionados países en los últimos siglos.

La noción de desarrollo surge inicialmente como sinónimo de crecimiento económico pero, muy pronto, diversos autores subrayaron que crecimiento no necesariamente significa mejor estar y que era absolutamente simplista aceptar que los comportamientos humanos se circunscribieran al "homo economicus" como agente en el mercado. Sobre la base de este razonamiento fueron agregando progresivamente elementos a la noción inicial hasta llegar al concepto de "desarrollo humano" que en alguna de sus ya numerosas versiones tiende actualmente a ser acogido por amplios sectores en los medios académicos y por algunas organizaciones internacionales como el Programa de las Naciones Unidas para el Desarrollo, PNUD $^{11}$.

En realidad, esta nueva aproximación al desarrollo no pretendía cuestionar a fondo la lógica del mercado, sino señalar cómo éste no resolvía muchos de los problemas que afrontan las sociedades contemporáneas y que, en consecuencia, por una parte debía rechazarse el "fundamentalismo" de quienes ven en ese instrumento la respuesta a todas las inquietudes humanas y la guía única de los procesos de construcción del futuro y, por otra parte, aceptar que, tal como lo había planteado Keynes, ante sus fallas -por lo demás propias de todo lo que es producto del ser humano-, era necesario aceptar intervenciones dirigidas a corregirlas.

\footnotetext{
${ }^{11}$ Entre los mejores resúmenes de esta evolución y de los elementos o “dimensiones” que han venido siendo incorporadas al concepto de desarrollo cabe mencionar los de Alkire (2002), Meier en Meier y Stiglitz (2002) y Martinussen (1997). Entre los autores más relevantes que han brindado elementos para la construcción del concepto de desarrollo humano se encuentran, por una parte, Sen cuyos diversos aportes están en gran parte recogidos en Desarrollo y Libertad (2000) y Ul Haq (1999) quien formuló la versión recogida por el PNUD; Max-Neef, Elizalde y Hoppenhayn (1996) y más recientemente Nussbaum (2005, 2007), Boltvinik (2007) y Gasper (2004).
} 
No obstante, no ha sido este el enfoque adoptado en la práctica política dominante en los ámbitos nacionales, en la esfera internacional y en el plano global. De hecho, en ellos ha prevalecido, en especial a partir del llamado Consenso de Washington (inicialmente formulado en 1989), la idea de que el desarrollo puede circunscribirse al crecimiento económico y que en la medida en que éste se ciña a los principios del mercado libre, se encargará de resolver paulatinamente los restantes problemas de la sociedad, derivados esencialmente de la carencia de recursos materiales para satisfacer las necesidades de la población ${ }^{12}$.

\section{Ética en el desarrollo}

La posición que acaba de presentarse -como cualquiera otra que involucre los comportamientos humanos- tiene implicaciones éticas. Si el mejor estar de la sociedad depende de una maximización eficiente de su actividad económica, ajustada a las leyes del mercado, cabe desprender dos corolarios, entre otros:

- El criterio para determinar si una determinada acción debe realizarse o no es el de la utilidad que genera. Ahora bien, siendo la utilidad social igual a al suma de las utilidades individuales, es claro que el cálculo de la primera no es otra cosa que la suma del cálculo de las rentabilidades individuales.

- El problema ético inherente a las decisiones económicas es resuelto por el mercado. Seguir sus orientaciones y exigir respeto a las mismas por parte de todos los agentes sociales constituye el primer compromiso de éstos.

Téngase en cuenta que la lógica de estos planteamientos es, al menos en una primera instancia, altamente favorable al capital en la medida en que los rendimientos son captados por los propietarios de éste y que, en cualquier hipótesis, la extensión de los beneficios al resto de la sociedad es producto bien sea de procesos de “derrame” del éxito económico hacia los grupos económicamente más débiles o de una intervención "a posteriori” de las autoridades públicas, intervención que sólo se acepta con grandes restricciones $^{13}$ y mientras se produce el ineludible efecto de "derrame".

Ahora bien, no es de extrañar que mientras ese efecto se concreta puedan darse situaciones de desprotección de diversos grupos sociales y

\footnotetext{
12 Tales principios, que de alguna manera se han convertido en la guía de referencia de la práctica política neoliberal abordan esencialmente los siguientes aspectos: disciplina fiscal; reordenamiento de las prioridades del gasto público, reforma tributaria, liberalización de las tasas de interés, del comercio internacional y de la entrada de inversiones extranjeras directas; tasa de cambio competitiva, privatización, desregulación y derechos de propiedad.

${ }^{13}$ Siguiendo los planteamientos de autores como Nozick y Hayek arriba mencionados.
} 
condiciones de alta asimetría entre sectores de la sociedad. No obstante, se insiste en el carácter temporal de tales situaciones y en la capacidad del libre mercado para resolverlas pese a las dudas que al respecto suscita la lectura de cifras como las mencionadas en la primera parte de este artículo.

Quienes sustentan estas ideas no carecen de argumentos. Wolff (2004), por ejemplo, hace énfasis en hechos como los siguientes:

- Si bien es cierto que el número de personas ubicadas bajo la línea de pobreza en el mundo ha venido creciendo, este crecimiento ha sido cada vez más lento y corresponde a un decrecimiento de esta población en términos relativos. Más aún, la reducción en términos absolutos ya comenzó para la población en condiciones de pobreza extrema.

- Aunque con excepciones, el ingreso por habitante de los distintos países ha venido aumentando desde principios de la década de los 90, y las tasas de crecimiento han sido más altas para el conjunto de los países económicamente atrasados que para el conjunto de aquellos que tenían mayor ingreso por habitante durante el período examinado. Las excepciones corresponden justamente a sociedades que por una u otra razón no se han insertado en la lógica de la economía global. Mal podría, en consecuencia, atribuirse a esta lógica su estancamiento o el deterioro de sus condiciones sociales.

El análisis anterior es rebatido por otros autores desde varias perspectivas. Entre los argumentos esgrimidos para ello se mencionan los siguientes:

- La crisis por la que atraviesa actualmente la economía mundial, iniciada en los países que han asumido el liderazgo de los procesos económicos recientes en el ámbito global, tiende a borrar los logros mencionados por Wolff ${ }^{14}$. De esta manera la situación ha retrocedido hasta llegar a ser lo que era hacia principios de los noventa y no hay evidencia alguna de que la situación haya tocado fondo.

- Desde un plano puramente económico, aunque se aceptara que la crisis actual es apenas un accidente coyuntural que podrá superarse con rapidez y que en poco tiempo se habrán recuperado las condiciones que se registraban en 2007, lo cierto es que la organización del mercado resultante de la globalización se aleja cada vez más de las condiciones de competencia perfecta que eran las llamadas a asegurar en el largo plazo el bienestar del conjunto de la población y la progresiva reducción de las disparidades en la distribución del ingreso no sólo entre países sino dentro de éstos.

- En una situación de competencia monopolística como la que ha venido imponiéndose, que rompe las fronteras nacionales para irrumpir en

${ }^{14}$ Las cifras presentadas en la primera parte de este artículo irían en apoyo de esta tesis. 
un ámbito global desprovisto de reglas claras y de árbitros al menos supuestamente imparciales para asegurar el juego limpio entre los actores económicos, en que la concentración del poder económico no sólo tiende a crecer sino a imponerse sobre el poder político dando forma a una realidad que no necesita sustentarse en los argumentos político-económicos de Marx $^{15}$, no es posible seguir actuando sobre la ficción de que el mercado es un instrumento capaz de asegurar condiciones generales de bienestar en el plano global. Así, por ejemplo, tal como lo señala Morin, (s. f.), la lógica de la rentabilidad, carente de una regulación ética y política adecuada para las condiciones del mundo hoy, es la que genera hoy toda la contaminación que pone en riesgo al conjunto del planeta.

- De todas maneras, tal como ya se indicó, para muchos resulta insostenible la pretensión de subordinar a lo económico la dinámica de los procesos sociales que es compleja como compleja es la naturaleza de la sociedad. Desde esta perspectiva, aún si en el largo plazo el proceso de crecimiento económico hiciera posible el acceso de todos los seres humanos a los bienes y servicios deseados y se hiciera realidad la llamada sociedad de consumo ${ }^{16}$, ello no bastaría para asegurar la calidad de las relaciones humanas, la libre expresión, la diversidad cultural, la armonía con la naturaleza y, en último término, la posibilidad de que cada uno logre su propia realización como individuo y como parte de la sociedad. La economía es un cierto modo de estudiar el actuar humano. Y se ocupa de cosas importantes. Pero no cubre sino una determinada parte de ese actuar. (Polo, 1997: 20).

\section{Ética e ideología}

Pero así como no es necesario acudir a Marx para entender el peso creciente de las decisiones económicas en la política global ${ }^{17}$, sí hay que

\footnotetext{
${ }^{15}$ Relativos a la determinación de la política (incluida dentro de la "superestructura” por la "estructura" dada por la organización de los procesos productivos.

${ }^{16}$ Autores como Rostow (1961) plantean como culminación del desarrollo este tipo de sociedad en el que todos sus miembros tienen posibilidad de acceder al consumo de los bienes y servicios de su preferencia.

${ }^{17}$ Varios análisis recientes van en apoyo al menos indirecto de esta afirmación. Stiglitz (2006: 16) señala que las cien empresas más grandes del mundo generan la tercera parte del PIB mundial y agrega, a título de ejemplo, que mientras en 2004, la cifra de negocios de Exxon era superior a la de 182 países miembros de las Naciones Unidas, en el año fiscal 2005, los grandes almacenes Wal-Mart tuvieron ingresos por 285.200 millones de dólares, es decir, más que la suma del PIB de todos los países del África Subsahariana. Por otra parte, según datos del Banco Mundial y Fortune Magazine para 2001 citados por Hernández (2009), de las cien unidades económicas más grandes del mundo (medido su tamaño por el PIB en el caso de los Estados y la cifra de negocios en el de las corporaciones), cincuenta y una eran firmas privadas. Esta constatación por cuestionada y cuestionable que sea la base de comparación utilizada, es relevante para cualquier reflexión sobre lo que implica en términos económicos, políticos y éticos el peso relativo, no siempre suficientemente reconocido, que tienen hoy las firmas multinacionales.
} 
volver a una de sus interpretaciones que, por incómoda, ha tendido a ser relegada al lugar de los desechos inútiles a pesar de su permanente actualidad: el concepto de “ideología”. Dicho de manera elemental, ideología es la apropiación y aprovechamiento de una teoría por un grupo social que se identifica con ella por cuanto coincide con sus intereses. Si este grupo social ocupa una posición dominante tiende a extender e incluso a imponer esa teoría por la razón o aún por la fuerza; en otros términos, hace un uso “ideológico” de ésta.

Un análisis de los planteamientos de la corriente dominante en el capitalismo contemporáneo pone de manifiesto el uso ideológico de los postulados éticos, en la medida en que ha logrado imponer en la mayor parte de mundo unos criterios de comportamiento que se presentan como condición para el beneficio colectivo aunque la realidad muestre cada vez con mayor claridad que con su aplicación se benefician principalmente ciertos grupos sociales, como se aprecia en las cifras mencionadas en la primera parte de este artículo.

Entre tales postulados se encuentran el carácter “científico” de la economía que no sólo permite al empresario sino que lo "obliga” en términos éticos. a cultivar su beneficio individual sin preocuparse por las consecuencias que sus actos pueden tener sobre los otros individuos y sobre la sociedad en su conjunto; la libertad, aplicada principalmente al ámbito económico, como valor supremo del ser humano que no puede ser afectado por otros valores, reales o supuestos como la equidad o la solidaridad; el individualismo, consecuencia en alguna medida de esa libertad, que induce a los agentes económicos ocuparse únicamente de su propio interés con el pretexto de que "la mano invisible" del mercado tiene respuestas y soluciones para cualquier dificultad de carácter colectivo; este instrumento, el mercado, como guía última y casi única de los comportamientos humanos y juez en última instancia de la racionalidad de éstos.

Algunos pocos textos de varios de los más connotados representantes de esta corriente sustentan el contenido del párrafo anterior. Robert Nozick, en primer lugar, (c1988) defiende un Estado mínimo "limitado a las funciones de protección contra la violencia, el robo, el fraude, la violación de contratos y otros parecidos...”, pero que no debe “...usar su aparato coercitivo con el propósito de lograr que algunos ciudadanos ayuden a otros, o para prohibirle a las personas actividades en su propio beneficio o protección”. Esto violaría su libertad. El Estado podría promover acuerdos distributivos entre los ciudadanos pero nunca obligarlos a redistribuir; cobrar impuestos con este propósito sería un robo porque arrebataría al individuo parte del fruto de su trabajo. Para Hayek, por su parte, el Estado de Derecho hace imposible alcanzar la justicia distributiva que considera opuesta a la conmutativa y que exigiría someter la totalidad de los recursos a las decisiones de una autoridad central. Dentro de los límites de ese Estado puede hacerse mucho para que el mercado funcione del mejor modo posible, lo que asegura la vigencia de la justicia conmutativa, pero "...lo que hoy se considera justicia distributiva no puede lograrse jamás.” (Hayek, 
1996:290). Si esto es así, resulta plenamente explicable la afirmación de Milton Friedman, según la cual: "Pocas tendencias podrían minar de una forma tan completa los mismos fundamentos de nuestra sociedad libre como el hecho de que los responsables de la empresa acepten una responsabilidad social en vez de intentar obtener los mayores beneficios posibles para sus accionistas”. (1962: 63)

Evidentemente, este tipo de planteamientos brindan argumentos poderosos para justificar la posición de los grupos que ocupan posiciones hegemónicas en la economía global. No es entonces sorprendente que al identificar los adalides de estas ideas, los escenarios en que las esgrimen y la manera como tienden a imponerlas en el ámbito global, se encuentre que detrás de la fachada de la "ciencia” están los intereses de los grupos que han resultado favorecidos por la lógica del capitalismo contemporáneo y, en particular, por sus expresiones dentro del mundo globalizado, al amparo de una institucionalidad pública puesta a su servicio principalmente desde que el Consenso de Washington se convirtió en el referente de las políticas públicas nacionales. ${ }^{18}$

Esto le ha permitido a Stiglitz afirmar que quienes se han adueñado del control de la globalización contemporánea están incurriendo en un nuevo fundamentalismo: el del mercado, que, por lo demás, se está aplicando de manera plenamente ideológica. A los países “en desarrollo" se les aseguró que la aplicación del Consenso les brindaría una prosperidad sin precedentes, cuando en la práctica ha enriquecido a unos pocos y ha generado mayor pobreza para los grupos que estaban en peores condiciones. El carácter ideológico de la propuesta se pone en evidencia por el hecho de que mientras los países ricos tienden a forzar a los países de menor desarrollo económico a eliminar las barreras comerciales, ellos, por su parte, alejándose de la teoría, mantienen las suyas frente a los productos procedentes de los países en vías de desarrollo, en especial los procedentes de la agricultura y continúan subsidiando a sus agricultores, mientras insisten en que los países en vías de desarrollo retiren los subsidios a sus productos manufacturados. (Stiglitz, 2003)

Naturalmente, frente a las posiciones que defienden a ultranza la irrestricta libertad de empresa y, hoy en día, bajo la égida de la globalización contemporánea, la movilidad de capitales, y -dentro de límites claramente fijados en función de los intereses de quienes los establecen- la libre movilidad de otros factores de producción y la circulación de bienes y servicios, no cabe una idea de justicia diferente a la que resulta del "libre" acuerdo de voluntades entre individuos. En otras palabras, y volviendo a Hayek, sólo la justicia conmutativa tiene razón de ser. Si las partes llegan a un acuerdo, cualquiera que sea, en que ninguna de ellas coaccione físicamente a la otra, es porque las condiciones del mercado validan los términos convenidos libremente entre quienes intervienen en ese acuerdo y porque, en conse-

${ }^{18}$ Cabe consultar al respecto la interesante discusión planteada por Edgard Reveiz (2004). 
cuencia, la suma de estos acuerdos entre individuos va a llevar a una situación social óptima.

No obstante, difícilmente podría afirmarse que todas las partes pueden expresar libremente su voluntad en ese tipo de acuerdos: seguramente los gobiernos que aceptan industrias o desechos contaminantes, a cambio de unos ingresos pasajeros, no tienen preferencia por esos residuos y si los admiten es porque carecen a corto plazo de otro tipo de alternativas de recursos que puedan aplicar para paliar algunas de las situaciones críticas a las que se ven abocados con frecuencia ${ }^{19}$. A lo sumo podría decirse que prefieren las basuras atómicas a la mortandad generada por una posible hambruna.

A propósito de esta afirmación cabe hacer una breve referencia a la ética de la cooperación internacional, regida en la práctica y muchas veces sustentada en la teoría por el llamado "realismo político" en las relaciones internacionales ${ }^{20}$. Según ella, estas relaciones “....se caracterizan por una lucha de poder entre sus miembros, quienes actúan de manera racional y egoísta, en aras de conseguir su interés nacional. En esta dinámica, los Estados colaboran con otros, no como un ejercicio de solidaridad sino como una estrategia de política exterior cuya finalidad consiste en satisfacer sus necesidades internas. Esto significa que desde esta perspectiva los Estados no tienen compromisos éticos extraterritoriales...” y que la cooperación para el desarrollo es sólo un mecanismo más de sus políticas exteriores para promover sus intereses políticos, económicos y geoestratégicos (Prado p.5). No es extraño así que la asistencia oficial al desarrollo se haya reducido sensiblemente a partir de la caída del muro de Berlín. ideologizada

El problema no es de falta de ética sino de una posición ética

\section{Planteamiento básico}

Con frecuencia se aduce que la enorme miseria material que se observa en el mundo de hoy es en gran parte debida a la falta de ética en los comportamientos humanos. No obstante, lo expuesto aquí permite sostener que esta afirmación no sólo es errada sino que de ser aceptada dentro de la lógica que actualmente domina el supuesto remedio: adoptar estrictamente la ética del mercado, va a empeorar la situación observada.

Para sustentar lo anterior hay que recordar que los actos humanos siempre tienen como referente criterios éticos: en el momento de tomar

\footnotetext{
${ }^{19}$ Resultan pertinentes esta línea las consideraciones y ejemplos de Ovejero (1994: 50-58)

${ }^{20}$ Esta referencia no implica el desconocimiento de otras teorías que se refieren a las relaciones internacionales como el neoliberalismo institucional y el constructivismo que pese a su interés no son las que dominan hoy en día el panorama de la cooperación internacional.
} 
cualquier decisión, la persona busca un resultado que normalmente considera positivo para sí o para otro. Ahora bien, esa connotación positiva que alguien le da a una acción u omisión no necesariamente coincide con el beneficio de otros individuos o del conjunto de la sociedad: ese alguien puede actuar, por ejemplo, para satisfacer su sed de venganza, que erróneamente considera positiva para sí, con lo que perjudica no sólo a quien golpea con su acción, sino a la sociedad, cuyas condiciones de convivencia perturba. No es exacto decir que ese individuo actuó sin ética; sí lo es afirmar que actuó bajo la influencia de principios éticos equivocados o que quebrantó conscientemente determinados principios éticos.

\section{Inequidad y ética en el mundo contemporáneo}

Cuando se examina el panorama del mundo contemporáneo desde la perspectiva del bienestar de sus habitantes y se plantean interrogantes tanto acerca del porqué de la iniquidad existente en el plano global y en el interior de las diversas sociedades, como acerca de la razón para que pese a lo aberrante de las situaciones que se viven actualmente, sigue en pie una férrea defensa de los principios que han conducido a ellas, es preciso dejar de lado respuestas simplistas como las que pretenden justificar los niveles de pobreza en la desidia de gran parte de la población o las que se limitan a ubicar a la sociedad en una etapa temprana del proceso de desarrollo que habrá de llevarla de manera ineluctable, hacia la meta deseada. Por el contrario, es necesario examinar más detenidamente la posición de quienes sostienen que son las faltas a la ética del mercado las que frenan el avance de la sociedad hacia el mejor estar de sus miembros. Según ellos, si se erradican los comportamientos que tratan de desviar o de eludir en beneficio propio las leyes del mercado, éste se encargará de resolver las carencias y de cerrar la brecha entre quienes todo lo tienen y quienes están desprovistos de todo. Sobre esto se volverá en breve pero antes se planteará una posición frente a los interrogantes enunciados.

\section{Los hechos son claros. Sintetizando lo ya expuesto:}

- Hay una quinta parte de la humanidad en situación de miseria y que no encuentra forma de salir de su condición, mientras los recursos existentes hoy en el mundo y que con frecuencia se malgastan, permitirían resolver a corto plazo el problema del hambre en el planeta. En palabras de Ghandi, “Tenemos suficiente para las necesidades de todos pero no para la codicia de unos pocos” (Citado por Elizalde s. f.)

- Casi la mitad de la humanidad está por debajo del umbral de lo que en el mundo de hoy se exige para una vida digna, pero, pese al compromiso formal de los Estados de contribuir al logro de los "Objetivos del Milenio" para superar algunas de las mayores carencias observadas, los avances han sido insuficientes y varias de las metas no serán alcanzadas. Esto es atribuible a la inacción de los actores públicos y privados que en la práctica las 
han relegan a un plano secundario frente a otras como máximo crecimiento económico o seguridad nacional.

- Mientras estas condiciones persisten, los mayores accionistas de las grandes corporaciones transnacionales continúan acumulando riquezas y se profundiza la brecha entre ellos y los miles de millones de personas que no logran los niveles mínimos de subsistencia.

\section{Ideología en la ética global}

Todo lo anterior ocurre mientras los Estados más poderosos y algunos organismos internacionales hacen esfuerzos para extender la vigencia de las normas y la ética del mercado según las orientaciones del Consenso de Washington. ¿Por qué esta insistencia? Independientemente de la validez de algunas de las medidas propuestas en ese instrumento, la única explicación lógica radica en el hecho de que como lo señala Stiglitz (2003, 2005) esas orientaciones y la ética implícita en ellas convienen a los intereses de esos Estados y de las grandes compañías transnacionales en las que ellos sustentan buena parte de su poder.

Se está en consecuencia en presencia de un aprovechamiento ideológico por parte de esas compañías y de esos Estados, de los planteamientos de la escuela económica neoliberal y de la ética que de ellos se desprende.

\section{Necesidad de una nueva ética para la economía global}

Ciertamente -con base también en el utilitarismo dominante- algunas personas han roto la ética del mercado ${ }^{21}$. Pero no son esos comportamientos desviados los que han conducido a la miseria y a las desigualdades existentes; una y otras son producto de la aplicación rígida de esa ética. En tal virtud, los graves problemas por los que atraviesa hoy la humanidad no se resuelven con un ataque frontal a los comportamientos que esa ética considera corruptos, aunque efectivamente haya que luchar por su erradicación. Lo que se requiere es una nueva lógica de funcionamiento de la economía que sin desconocer el mercado, institución que hasta el momento ha resultado ser la más eficaz para organizar las transacciones, tenga en cuenta la naturaleza social y multidimensional del ser humano y el carácter necesariamente ético de sus decisiones en cualquier campo. Estas afirmaciones requieren una sustentación adicional.

En primer lugar, una observación de las tendencias recientes en el mundo muestra que el abismo descrito entre los grupos sociales que se

\footnotetext{
${ }^{21}$ Los recientes escándalos en grandes corporaciones, que han contribuido grandemente a la actual crisis económica mundial son ejemplo de estas desviaciones.
} 
encuentran en los extremos de la abundancia y la miseria, lejos de cerrarse tiende a profundizarse con el tiempo. Es posible afirmar que la evolución de la economía global ha paralizado la mano invisible que según Adam Smith debía conducir al bienestar colectivo, y ha introducido los procesos económicos en un círculo en el que las desigualdades tienden a ahondarse progresivamente y a estancarse la miseria en que se debate gran parte de la población mundial. Ahora bien, hay razones, ya mencionadas, para sostener que en esta evolución se observa la influencia de los principios éticos de carácter utilitarista, libertario e individualista propios de la ética del mercado. Es válido, en consecuencia, argumentar que para salir de ella se requieren intervenciones que actúen con criterios éticos diferentes.

En segundo lugar, si el proceso de desarrollo es más que crecimiento económico, el intento de seguir tratando de someterlo a normas de naturaleza puramente económica y basadas exclusivamente en la individualidad del ser humano, resulta contraproducente para avanzar en la búsqueda de una sociedad más armónica. Esta observación cobra mayor validez cuando se considera que en opinión de sus más radicales defensores, estas normas son leyes científicas que excluyen en el proceso decisorio, consideraciones de tipo valorativo diferentes al cálculo de rentabilidad.

En tercer lugar, si el proceso de desarrollo tiene un horizonte de largo plazo que no está predeterminado por leyes científicas, es la sociedad humana la que debe escoger el escenario hacia el cual ha de dirigirse y el camino para llegar a él. No tendría sentido orientarse únicamente por cálculos de rentabilidad inmediata, seguramente válidos para tomar decisiones sobre acciones de corto plazo pero no para orientar el curso de acciones con horizontes temporales más amplios.

Para terminar, los cambios ocurridos en la sociedad mundial a lo largo del siglo XX, impulsados en las últimas décadas por la globalización, han transformado el mundo de una manera tan profunda, que no es posible suponer que los procesos de crecimiento y desarrollo que vivieron las sociedades que hoy se consideran más avanzadas desde un punto de vista económico, hayan de ser repetidos por las que hoy ocupan los lugares de retaguardia en términos de su evolución económica. En particular, las imbricaciones transnacionales de las redes sociales, económicas y políticas hacen cada vez menos probable que este último grupo de sociedades pueda trazar y recorrer, como de alguna manera lo hicieron muchos de los países económicamente más avanzados, la vía de su propio desarrollo económico. Todo lo anterior conduce a plantear la necesidad de revisar no sólo el funcionamiento sino la lógica propia del mercado global y, por ende los principios éticos que lo rigen ${ }^{22}$.

\footnotetext{
${ }^{22}$ Aunque no hace parte del tema de este artículo, hay que tener en cuenta que el funcionamiento del mercado global difiere considerablemente de los mercados nacionales. Baste señalar tres características que lo distinguen de éstos, sin pretensión de que ellas sean las más importantes para la reconceptualización, por lo demás en curso, de esta institución
} 
En cualquier caso, la respuesta a los interrogantes arriba formulados pasa por el examen de los criterios que sustentan las acciones de los diferentes agentes que lideran los procesos contemporáneos de desarrollo. A partir de este examen es posible afirmar que tales criterios no permitirán el desarrollo humano de gran parte de la población, aún si su aplicación condujera en el mediano o en el largo plazo a resolver las condiciones básicas de subsistencia de esa población, ya que inclusive bajo esa hipótesis, la más optimista de todas, las disparidades de poder económico y político harían insuperable la posición subordinada de la inmensa mayoría de los habitantes del planeta.

\section{Conclusiones}

Lo expuesto permite plantear las siguientes conclusiones:

- La evolución de la sociedad humana no ha sido producto de fuerzas ineluctables que obedezcan a leyes "científicas" como supuestamente serían las que rigen el funcionamiento del mercado capitalista, sino de la voluntad relativamente libre de seres humanos que ocupan posiciones diferentes en poder dentro de esa sociedad.

- Dentro de la lógica del capitalismo imperante en los países occidentales y que tiende a extenderse a la mayor parte del mundo, las decisiones económicas se han sustentado en una ética individualista, de carácter utilitarista, en la que el rendimiento económico es el criterio fundamental para las decisiones y en que la idea de justicia queda reducida al cumplimiento de acuerdos entre agentes económicos, independientemente de las condiciones de cada uno y del contexto que los rodee.

- Los aspectos indeseables de la evolución de la sociedad humana en el mundo de hoy no son producto de una falta de ética sino de la aplicación de principios éticos inadecuados que desconocen la naturaleza social del ser humano y tienden a condicionar todos sus aspectos a la satisfacción de sus necesidades materiales mediante la lógica del mercado.

- El desarrollo, entendido como un proceso social que significa avance hacia un futuro mejor, va mucho más allá de lo meramente económico y en tal virtud, sus orientaciones éticas y políticas no pueden limitarse a las

económica fundamental en el sistema capitalista, democrático y liberal que impera en los países occidentales y que en algunos aspectos ha venido extendiéndose al resto del mundo. Estas características son: la imposibilidad práctica de alcanzar la competencia perfecta como situación ideal; el auge de las cadenas y redes productivas y de valor -que incorporan inclusive elementos no económicos de su entorno- como agentes económicos por encima del establecimiento individual y, como corolario de lo anterior, el surgimiento de nuevas formas de competencia y cooperación entre las firmas (coopetencia) que obligan a replantear la concepción puramente individualista que ha presidido la ética del mercado. 
que se desprenden del mercado, así éste no haya encontrado hasta ahora un sustituto válido como guía de los procesos económicos.

- La concepción aún predominante de la ética del mercado, basada en el supuesto carácter científico de la economía, pudo tener sentido -en el mejor de los casos- en los ámbitos nacionales. Aparte de que hoy necesita un replanteamiento que le permita acomodarse a las exigencias de un mundo globalizado, la pretensión de convertirla en criterio definitivo para el conjunto de los comportamientos humanos no sólo resulta inaceptable sino que tiene un carácter completamente ideológico en el sentido propuesto por Marx.

- La justicia como valor ético fundamental va más allá de un simple acuerdo de voluntades entre agentes económicos que refleje las condiciones del mercado. Ella exige satisfacer, ante todo las exigencias que corresponden a la "dignidad" propia de todo ser humano.

Sintetizando, el proceso que hoy se conoce como desarrollo no puede realizarse plenamente si no tiene la justicia, valor ético fundamental, como uno de sus referentes esenciales. Este valor no desconoce pero sí trasciende las expresiones particulares de la justicia conmutativa, en la medida en que es la justicia distributiva la que apunta directamente a garantizar la dignidad de cada uno de los seres humanos, base de la convivencia y el desarrollo. 


\section{Bibliografía}

Abascal Salvador, Chica Ricardo et al. (1994), Ética y Economía, Centro Editorial Javeriano, CEJA, Bogotá.

AISLAC 80, Medicamentos en http://www.aislac.org/pdf/boletin_correoais/ bol-aislac85.pdf.

Alkire Sabina (2002), "Dimensions of human development", World Development, Vol. 30 \# -2: 181-205, Pergamon, Elevier Science Ltd., Great Britain 2002.

Angulo Novoa Alejandro (1994), Ética, Solidaridad, Ecología. De la posibilidad a la probabilidad del desarrollo, Cinep, Santa Fe de Bogotá. Aranguren José Luis (1996), Ética y Política, Biblioteca Nueva, S. L., Madrid.

Arnsperger Christian y Van Parijs Philippe (2002), Ética económica y social. Teorías de la sociedad justa", Ediciones Paidós Ibérica S.A., Barcelona.

Banco Mundial (2004), Desarrollo y reducción de la pobreza. Mirada retrospectiva y panorama futuro, Wolfensohn James D, Presidente del Banco, Washington.

Idem (2008), "The developing world is poorer than we thought, but no less successful in the fight against poverty", documento preparado por Ravallion y Chen, disponible en sitio web http:// siteresources.worldbank.org/DEC/Resources/Poverty-Brief-in-Spanish.pdf,

Idem (2009 a), Global Monitoring Report 2009. A Development Emergency", Washington.

Idem (2009 b), Informe sobre seguimiento mundial 2009, Resumen, Washington.

Barry Brian (1992), La teoría liberal de la justicia. Examen crítico de las principales doctrinas de Teoría de la justicia de John Rawls, Colección Fondo de Cultura Económica, México.

Boltvinik Julio (2007), “De la pobreza al florecimiento humano: ¿teoría crítica o utopía?” en Desacatos, No. 23, enero-abril 2007, México.

De Zan Julio (2004), La ética, los derechos y la justicia, Fundación Konrad Adenauer, Uruguay, Montevideo.

Elizalde Antonio, (s. f.), Desarrollo sustentable y consumo, Presentación de Power Point en http://www.pedagogiasocial.cl/textos/ DS\%20y\%20consumo.ppt 
Filgueira Carlos, Peri Andrés (2004), América Latina: los rostros de la pobreza y sus causas determinantes, CEPAL, Santiago de Chile.

Friedman Benjamin M. (2005), The Moral Consequences of Economic Growth, Alfred A. Knopf, New York

Friedman Milton y Rose (1983), Libertad de elegir, Ediciones Grijalbo S. A., Ediciones Orbis, Barcelona.

Fukuda-Parr Sakiko y Shiva Kumar A.K. (2005), Readings in Human Development, Human Development Report Office, United Nations Development Program, Oxford University Press, New Delhi.

Gasper Des (2004), The ethics of development. From economism to human development, Edinburgh Studies in World Ethics, Edinburgh University Press, Edinburgh.

Idem (2006), "What is the point of Development Ethics?” in Ethics and Economics, No 4, vol. 2

Idem (2007), "Human Rights, Human Needs, Human Development, Human Security. Relationship between four international 'human' discourses”, Forum for Development Studies, 1

Gasper Des, Trahn-Dam Thuong, (2005), “Deepening development ethics: from economism to human development, to human security”, European Journal of Development Research, 2005, 17(3), 372-384.

Golcin Ian, Reinert Kenneth (2007), Globalización para el Desarrollo, Banco Mundial, Editorial Planeta Colombiana S. A., Bogotá

Gómez-Heras José M. (2002), Ética en la frontera, Editorial Biblioteca Nueva S.L., Madrid, 2002.

González Jorge Iván (2006), Ética, economía y políticas sociales, Corporación Región, Medellín.

Hall Anthony y Midgley James (2004), Social Policy for Development, Sage Publications, Cornwall, Great Britain.

Hayek, Friedrich August von, (c1990), La fatal arrogancia: los errores del socialismo, Unión Editorial, Madrid.

Idem (1996), Los fundamentos de la libertad, Ediciones Folio, Barcelona.

Hernández Zubizarreta Juan (2009), Las empresas transnacionales frente a los derechos humanos: historia de una asimetría normativa. De la responsabilidad social corporativa a las redes contrahegemónicas transnacionales, Zubiria Etxea. UPV/EHU, Observatorio de las Multina- 
cionales en América Latina, Asociación Paz con Dignidad, Bilbao, Madrid. En http://pdf2.hegoa.efaber.net/entry/content/434/ las_empresas_transnacionales_juan_hernandez.pdf

Hertz Noreena (2001), The silent takeover: global capitalism and the death of democracy, Free Press, New York.

Kliksberg Bernardo, (s. f.) ¿Es Posible Construir una Economía con Rostro Humano?, Banco Interamericano de Desarrollo, Biblioteca Digital de la Iniciativa Interamericana de Capital Social, Ética y Desarrollo, www.iadb.org/etica.

López Michelsen Alfonso (1966), La estirpe calvinista de nuestras instituciones, Tercer Mundo, Bogotá.

Martinussen John (1997), Society, State \& Market A guide to competing theories of development”, Zed Books, London.

Max-Neef Manfred, Elizalde Antonio, Hoppenhayn Martín (1986), Desarrollo a escala humana: una opción para el futuro, Número especial de Development Dialogue, Fundación Dag Hammarskjöld - CEPAUR, Uppsala.

Meiier G y Stiglitz J. (2002), Fronteras en la Economía del Desarrollo. El Futuro en Perspectiva, Banco Mundial, Alfaomega, Bogotá.

Mknadawire Thandika, (editor), (2005), Social policy in a development context, UNRISD, Palgrave Macmillan, Nueva York.

Morin Edgar (s. f.), “Estamos en un Titanic”, Banco Interamericano de Desarrollo, Biblioteca Digital de la Iniciativa Interamericana de Capital Social, Ética y Desarrollo, www.iadb.org/etica.

Naciones Unidas (2008 a), Objetivos de desarrollo del Milenio, Informe 2008, New York

Idem (2008b), Evento de alto nivel sobre los Objetivos de Desarrollo del Milenio, 25 septiembre 2008, Nueva York, en http://www.un.org/spanish/ millenniumgoals/pdf/MDGreportreleaseSPANISH.pdf

Idem (2008c), Informe del Grupo de Tareas sobre el desfase en el logro de los objetivos de desarrollo del Milenio de 2008, Objetivo de desarrollo del Milenio 8, Nueva York

Nozick, Robert (c1988) Anarquía, Estado y Utopía, Fondo de Cultura Económica, México, D.F.

Nussbaum Martha, (2005) Capacidades como titulaciones fundamentales: Sen y la justicia social Universidad Externado de Colombia, Bogotá. 
Idem (2007) Las fronteras de la justicia: consideraciones sobre la exclusión, Paidós, Barcelona.

Idem (1996) con Sen Amartya (editora), La calidad de vida, Fondo de Cultura Económica, México.

Organización de las Naciones Unidas para la Agricultura y la Alimentación, FAO (2008), El estado mundial de la agricultura y la alimentación 2008, Informe anual, Roma.

Idem (2009), Comunicado de Prensa, Oficina Regional para América Latina y el Caribe, Santiago de Chile, 19 de junio de 2009.

Organización Mundial de la Salud, OMS (2008 a), Informe sobre la salud en el mundo 2008- La atención primaria de salud: Más necesaria que nunca.

Idem (2008 b) El efecto de las crisis mundiales en la salud: dinero, clima y microbios, Discurso de la Directora General Margaret Chan en el vigésimo tercer Foro sobre asuntos de interés mundial, Berlín (Alemania), 18 de marzo de 2009.

Ovejero Félix (1994), Mercado, Ética y Economía, TESYS S. A.

Peces-Barba Gregorio (1995), Ética, poder y derecho. Reflexiones ante el fin de siglo, Centro de Estudios Constitucionales, Artegraf, Madrid.

Polo Leonardo (1997), Ética. Hacia una versión moderna de los temas clásicos, Unión Editorial, Segunda Edición, Madrid.

Prado Lallande Juan Pablo (s.f), La dimensión ética de la cooperación internacional al desarrollo. Entre la solidaridad y el poder en las relaciones internacionales, Banco Interamericano de Desarrollo, Biblioteca Digital de la Iniciativa Interamericana de Capital Social, Ética y Desarrollo, www.iadb.org/etica

Procacci Giovanna (1999), “Ciudadanos pobres, la ciudadanía social y la crisis de los estados del bienestar”, en García Soledad, Lukes Steven (compiladores), Ciudadanía: justicia social, identidad y participación, páginas 15-44, Siglo XXI de España Editores, Madrid-México.

Rapley John (2004), Globalization and Inequality, Neoliberalism's Downward Spiral, Lynne Rienner Publishers, Colorado, USA

Rawls John, (1986), Justicia como Equidad. Materiales para una Teoría de la Justicia, Tecnos.

Idem (1995), Teoría de la Justicia, Fondo de Cultura Económica, México Raz Joseph (2001), La ética en el ámbito público, Gedisa editorial, Barcelona.

Revéiz Edgar, (2004), El Desenlace Neoliberal: Tragedia o Renacimiento”, Esfera editores, Bogotá. 
Rostow, Walt Whitman (1961), Las etapas del crecimiento económico, Fondo de Cultura Económica, México.

Sen Amartya, (1997), Bienestar, justicia y mercado, Pensamiento contemporáneo, Paidós, Barcelona.

Idem (2000) Desarrollo y Libertad, Planeta Colombiana Editorial S. A., Santafé de Bogotá.

Idem (1989) Sobre Ética y Economía, Alianza Editorial, Madrid.

Paul Shaffer (2008), New Thinking on Poverty: Implications for Globalization and Poverty Reduction Strategies DESA Working Paper No. 65ST/ESA/2008/DWP/65, Department of Economic and Social Affairs, United Nations.

Short Clare (2009), The grave challenge facing the international humanitarian system - a personal view, en "Journal of Global Ethics", Volume 5, Number 1, April 2009, Routledge, Alberytswyth, Great Britain. Sklair Leslie (2002), Globalization. Capitalism and its Alternatives, Oxford University Press.

Slaughter Anne-Marie (2005), A New World Order, Princeton University Press, USA.

Stiglitz Joseph (2003), El malestar en la globalización, Santillana Ediciones Generales SL, Madrid.

Idem (2005) Los felices 90. La semilla de la destrucción, Santillana Ediciones Generales SL, Madrid.

Idem (2006) “La corporación multinacional”, Claves de razón práctica, Generalitat valenciana, No. 167, 2006b: 16-27.

Ul Haq Mahbub (1999), Reflections on Human Development, Oxford University Press, Oxford.

Van Parijs, Philippe (1995), “Más Allá de la Solidaridad. Los Fundamentos Éticos del Estado de Bienestar y de su Superación” en Lo Vuolo R., Contra la Exclusión. La Propuesta del Ingreso Ciudadano, Miño y Dávila editores, Buenos Aires.

Weber Max, (c2001), La ética protestante y el espíritu del capitalismo, Alianza Editorial, Madrid.

Wolf Martin (2004), Why Globalization Works, Yale University Press, Bolton, USA.

Zañartu Mario (1994 a), “Relaciones entre ética y economía. Estado del 
Polis, Revista de la Universidad Bolivariana, Volumen 8, $N^{\circ}$ 23, 2009

problema desde la ciencia económica” en Abascal, Chica y otros, (1994).

Idem (1994 b), "El ethos requerido para una transformación productiva con equidad” en Abascal, Chica y otros, (1994). 